\title{
Effect of Cinnamon, Cardamom, Saffron and Ginger consumption on the marker of endothelial function and blood pressure in type 2 diabetes mellitus patients: A randomized controlled clinical trial
}

Paria Azimi ${ }^{1,2}$, Reza Ghiasvand ${ }^{1,2}$, Maryam Bahreynian ${ }^{1,2}$, Mitra Hariri ${ }^{1,2}$,Javad Hosseinzadeh ${ }^{1,}$

${ }^{2}$, Hossein Khosravi-Boroujeni ${ }^{3}$

${ }^{1}$ Food Security Research Center, Isfahan University of Medical Science, Isfahan, Iran

${ }^{2}$ Department of Community Nutrition, School of Nutrition and food science, Isfahan University of Medical Science, Isfahan, Iran

${ }^{3}$ Population and Social Health Research Program, Menzies Health Institute Queensland and School of Medicine, Griffith University, Australia

Running title: herbal and endothelial function and blood pressure

Correspondence to: Reza Ghiasvand, $\mathrm{PhD}$

Department of Community Nutrition

School of Nutrition and Food Science

Isfahan University of Medical Sciences

Isfahan PO Box 81745-151

Iran

Tel: +98-311-7922720

Fax: +98-311-6682509

Email: ghiasvand@hlth.mui.ac.ir

Alternate email: rghiasvand@yahoo.com 


\begin{abstract}
Introduction: Type 2 diabetes mellitus (T2DM), the fourth cause of death in developed countries, affected $11.4 \%$ of the Iranian adult population. Herbal medicines with high amount of phytochemicals have beneficial effects on diabetes' complications. The present study aimed to determine the effect of herbal treatment on endothelial function and blood pressure in T2DM patients.
\end{abstract}

Methods: This single-blind randomized controlled clinical trial included 204 T2DM patients. These patients were randomly assigned to four groups of intervention, receiving either three grams of cinnamon, or cardamom, or ginger, or one gram of saffron, with three glasses of black tea and one control group which consumed only three glasses of tea without any herbals for 8 weeks. Intercellular Adhesion Molecule-1(ICAM-1), systolic and diastolic blood pressure and anthropometric measures were collected at baseline and after 8 weeks of intervention.

Results: We found a significant effect of saffron $(340.9 \pm 14.4 \mathrm{ng} / \mathrm{ml}$ vs. $339.69 \pm 14.4 \mathrm{ng} / \mathrm{ml}$, $\mathrm{P}=0.01)$ and ginger consumption on sICAM-1 concentrations $(391.78 \mathrm{ng} / \mathrm{ml} \pm 16.0 \mathrm{vs}$. $390.97 \pm 15.8 \mathrm{ng} / \mathrm{ml}, \mathrm{P}=0.009)$, and ginger intake on systolic blood pressure $(143.6 \pm 0.2$ mmHg vs. $142.7 \pm 0.2 \mathrm{mmHg}, \mathrm{P}=0.02$ ). In terms of anthropometric measures, cinnamon consumption reduced weight, and cardamom and ginger intake diminished waist circumference but none of them were statistically significant ( $p$-value $>0.05$ ).

Conclusions: Although administration of cinnamon, cardamom, saffron and ginger as a supplementary remedy could affect blood pressure and sICAM-1 concentrations, there was no significant difference between various medicinal plants in terms of influencing anthropometric measures, blood pressure, and endothelial function.

Keywords: Diabetes mellitus type 2, blood pressure, endothelial function, cinnamon, cardamom, saffron, ginger. 
Registration number: IRCT201206185062N5

\section{INTRODUCTION}

Type 2 diabetes mellitus (T2DM), which is highly prevalent around the world ${ }^{(1)}$, affects $6 \%$ of the world's adult population ${ }^{(2)}$. In Iran, its prevalence is $11.4 \%$ among adults aged $25-70$ years(3). Diabetes is characterized by elevated oxidative stress, endothelial dysfunction and hypertension that may lead to diabetic complications, including coronary vascular disease $(\mathrm{CVD})^{(4)}$. Type 2 diabetes increases the risk of coronary heart disease two to four times ${ }^{(5)}$. ICAM-1 is the most well-known adhesion molecule, and it causes the firm attachment of leukocytes to endothelial and increases their trans endothelial migration. ICAM-1 is one of the the best biomarkers for recognition of atherosclerotic plaque progress in diabetes type 2 people. ${ }^{(6)}$.

Lifestyle modification, including dietary management, might be helpful in controlling diabetic complications. Among others, herbal medicines have been reported as beneficial to reduce blood pressure and improve endothelial function ${ }^{(7,8)}$.

Cinnamon is known to be one of the functional foods with phytochemicals and flavonoids that may help improve blood circulation, endothelium relaxing ability, and increase vascular smooth-muscle relaxation $^{(9,10)}$. Findings from a meta-analysis have revealed that cinnamon and components of cinnamon were beneficial to reduce systolic and diastolic blood pressure $^{(11,12)}$.

Cardamom, another herbal medicine, contains bioactive components that have been found to have antihypertensive potential that might influence diabetes complications ${ }^{(13)}$. It seems that these components effectively decrease blood pressure through enhancement of fibrinolysis 
and cholinergic ${ }^{(13,14)}$. However, reports on the effectiveness of the cardamom on endothelial function are limited.

Saffron, which contains crocetin, is used in treating various conditions such as heart and blood disorders, and dyslipidemia ${ }^{(15)}$.In an in vitro study, crocetin decreased serum LDL and malondialdehyde (MDA) levels and may prevent the formation of atherosclerosis and improve endothelial function $(15,16)$. The blood pressure lowering effect of saffron has been attributed to its components like crocin, crocetin and safranal ${ }^{(13,17)}$.

Ginger has also been found to have antihypertensive effects due to it containing 6-shogaol and 9-gingerol which inhibit formation of sticky plaque and increase the elasticity of arteries through the reduction of LDL and total-cholesterol levels ${ }^{(14)}$. In addition, ginger has been reported to reduce serum sICAM-1 levels by reducing the release of inflammatory mediators which lead to endothelial dysfunction ${ }^{(18)}$.

Although individual reports are available, indicating the effect of these herbal medicines on metabolic profile, no comprehensive report exists comparing the beneficial effects of these herbals on diabetes' complications. This study, therefore, aimed to comparatively examine the effects of cinnamon, cardamom, saffron and ginger consumption on markers of endothelial function and blood pressure in diabetic patients.

\section{MATERIALS AND METHODS}

Patients: This is a parallel, randomized, single-blind, placebo controlled, clinical trial, conducted among 208 people with T2DM (fasting blood glucose $\geq 126 \mathrm{mg} / \mathrm{dL}$ ) for eight weeks from October 2012 through September 2013. People with diabetes who referred to the Endocrine and Metabolism Research Center of Isfahan University of Medical Sciences, were screened for the inclusion criteria of this study. Individuals were included in the current study 
if they were 30 years or older, had been diagnosed with type 2 diabetes, were overweight $(\mathrm{BMI} \geq 25 \mathrm{~kg} / \mathrm{m} 2)$ and not on insulin therapy and not taking medications except for OHSAs (Metformin and Glibenclamide). Participants were excluded if they had planned to get pregnant. In addition, those needing to start insulin therapy during intervention and individuals who were consuming special spices (cinnamon, cardamom, ginger and saffron) during the running period were excluded. All participants provided informed written consent and the Ethics Committee of the university ethically approved the study. The trial has been registered in the Iranian Registry of Clinical Trials website at http://www.irct.ir (IRCT201206185062N5). A sample size of 200 participants was calculated to detect a difference between groups in terms of blood pressure and endothelial function. Considering dropouts, we selected two hundred and eight people based on the inclusion and exclusion criteria.

Study design: All participants were entered into a run-in period of three weeks to make their tea consumption pattern identical because tea was the main carrier of the herbals we used in the study. For allocation of the participants, a permuted block method was used. Participants were randomly assigned into four groups of intervention, receiving either three grams of cinnamon, cardamom, or ginger or one gram of saffron, and one control group. All participants received the given amounts of herbal medicines in three glasses of black tea (Golestan tea bags, Golestan Inc.). Participants in the control group received three glasses of tea without any herbals. This amount of herbal medicine was a safe dose and selected from previous studies. We administered herbals as a raw, dried powder of Cinnamon (Cinnamomum verum) sticks (inner bark of tree), green cardamom (cardamomum) small seed pods, saffron (saffron crocus) stigmas of the Crocus sativus flower and ginger (Zingiberaceae) rhizome of the Zingiber officinale plant. All spices used in the current study were approved by the Ministry of Health (License No.16/13777). 
Patients received the herbal medicines in plastic packs containing 3 grams of the given herbs (Cinnamon or cardamom or ginger) or 1 gram of saffron combined with black tea. Patients were educated to stew these herbals with black tea in a traditional way (in the kettle for 10 minutes) three separate times throughout the day. Compliance was assessed through phone interviews and through taking dietary records. All patients were requested to follow their usual diets without any changes. To make sure that the changes in dietary intakes could not influence the findings, we asked participants to record their dietary intakes (including tea consumption and the herbal medicine) for five separate days throughout the intervention. A one-day dietary record was taken at the study baseline and the four remaining were taken every two weeks. In order to collect data on physical activity levels, a short IPAQ (International physical activity questionnaire) (19) was administered throughout the intervention to all participants. These questionnaires were completed by trained nutritionists.

Assessment of blood pressure: Blood pressure was assessed by an analog barometer in the midpoint of the upper arm at the level of the heart. A blood pressure cuff was wrapped snugly around the upper arm and the lower edge of the cuff was 1 inch above the bend of the participants elbow. The subjects had to be comfortably seated with their back supported and their legs uncrossed, with the feet resting firmly on the floor. Blood pressure was measured after a period of rest (at least 5 minutes), not immediately after exertion or ingestion of coffee or use of tobacco in the previos 30 minutes. Following these BP measurements, one other measurement was taken, 5 minutes after the first, a third BP was measured if more than 5 mmHg difference in SBP between the two readings was noted, and the mean of the two closest was taken as the valid BP. Measurements were performed on the same arm baseline and after 8 weeks of intervention.

Assessment of biochemical indicators: At the study baseline and after 8 weeks of intervention, $15 \mathrm{~mL}$ fasting blood samples were taken and placed into tubes. Blood samples 
were centrifuged immediately and serum samples were stored in $-70 \dot{\mathrm{C}}$ until analysis. To assess endothelial function, we quantified serum sICAM-1 levels by using commercially available ELISA kits. The inter- and intra-assay coefficients of variations for this biomarker were $7.66 \%$ and $4.1 \%$, respectively.

Assessment of other variables: All required information about demographic characteristics and anthropometric measures were collected through pretested questionnaires. Weight was measured at minimally clothed status without shoes to the nearest 100 grams with digital Seca scale. Height was measured in a standing position without shoes, using a tape meter to the nearest $0.5 \mathrm{~cm}$. Body Mass Index (BMI) was calculated as weight in kilograms divided by the square of height in meters. Waist circumference was measured with a flexible tape, at the level of the umbilicus, and was recorded to the nearest millimeter.

Statistical methods: Analysis were performed with the SPSS version 16(spssInc, Chicago,IL). Quantitative data are shown as Mean \pm SE. One way multivariate analysis of variance (or covariance as appropriate) (MANCOVA), followed by Dunnett's post hoc pairwise comparisons test were used. Within group comparisons were done using paired samples t-test. Normality distribution of data was evaluated using Kolmogorov-Smirnov test. For non-normal data, log transformation was conducted. P values less than 0.05 were considered statistically significant.

\section{RESULTS}

From 208 patients enrolled in the study, four patients were excluded due to the lack of a blood sample at the end of trial. No adverse reactions were reported from the consumption of herbal medicines throughout the study. Baseline characteristics and physical activity levels of study participants across different groups are shown in Table 1. There were significant differences in age and weight when comparing the five groups; such as individuals in the 
saffron group being slightly older than those in other groups. In addition, patients in the saffron group were more obese than those in other groups. No other significant differences were seen across the five groups in terms of other characteristics. Comparing the five groups, no significant difference in mean physical activity (MET-h/wk) was observed.

Dietary intakes of study participants, based on five-day dietary records, throughout the intervention are shown in Table 2. We did not find any significant difference in energy intakes, macro- and micronutrients when comparing the five groups. The mean energy intake in study participants were mostly around $2300 \mathrm{kcal} / \mathrm{d}$.

The effect of herbal medicines on anthropometric measures, blood pressure and serum sICAM-1 concentrations is provided in Table 3. As there was a significant difference in age and weight at study baseline comparing the five groups, all analyses were controlled for the baseline levels of these measures. When we compared the effect of different herbal medicines, we failed to find any significant effect of these medicines on anthropometric measures, blood pressure and serum sICAM-1 levels. However, within-group comparisons revealed a significant effect of saffron (baseline: $340.9 \pm 14.4 \mathrm{ng} / \mathrm{ml}$ vs. end of trial $339.69 \pm$ $14.4 \mathrm{ng} / \mathrm{ml}, \mathrm{P}=0.01$ ) and ginger intakes on sICAM-1 concentrations (baseline: $391.78 \pm 16.0$ $\mathrm{ng} / \mathrm{ml}$ vs. end of trial $390.97 \pm 15.8 \mathrm{ng} / \mathrm{ml}, \mathrm{P}=0.009$ ), and a significant effect of ginger on systolic blood pressure (baseline: $143.6 \pm 0.2 \mathrm{ng} / \mathrm{ml}$ vs. end of trial $142.7 \pm 0.2 \mathrm{ng} / \mathrm{ml}$, $\mathrm{P}=0.02$ ). In addition, cinnamon intake tended to affect weight (baseline: $75.62 \pm 1.2 \mathrm{~kg}$ vs. end of trial $75.32 \pm 1.2 \mathrm{~kg}, \mathrm{P}=0.07$ ), while cardamom and ginger intakes tended to influence waist circumference (baseline: $101.47 \pm 1.4 \mathrm{~cm}$ vs. end of trial $101.07 \pm 1.4 \mathrm{~cm}, \mathrm{P}=0.09$ and baseline: $104.56 \pm 1.3 \mathrm{~cm}$ vs. end of trial $104.17 \pm 1.3 \mathrm{~cm}, \mathrm{P}=0.06$ respectively). No other significant effect of medicinal plants was observed on other outcome variables. 


\section{DISCUSSION}

In the current study, we found that there was no significant difference between various medicinal plants in terms of influencing anthropometric measures, blood pressure, and serum sICAM-1 concentrations and these results indicate that our herbal remedies cannot be useful in preventing CVD in diabetic patients. However, saffron and ginger intakes significantly reduced sICAM-1 concentrations and ginger intake affected systolic blood pressure. In addition, cinnamon intake tended to affect weight and cardamom and ginger intakes tended to influence waist circumference. These findings were obtained after controlling for age and baseline weight. A lack of finding a significant difference in physical activity and dietary intakes of study participants throughout the study indicates a good compliance of the study participants to the study procedures.

Endothelial dysfunction plays a critical role in the pathogenesis of diabetes' vascular complications $^{(20)}$. Earlier studies had shown an increase in levels of sICAM-1 in diabetic patients $^{(21)}$. We found that saffron and ginger intake, for eight weeks led to reduced sICAM-1 concentrations compared to the study baseline. The significant effect of saffron might be explained by its high content of crocetin. Earlier studies have shown that crocetin could significantly down-regulate sICAM-1 protein expression ${ }^{(22)}$. No further study is available indicating the efficiency of saffron intake or its ingredients on endothelial function. Considering the usual intake of saffron in some parts of the world, it seems necessary to further examine the effect of this herbal medicine and its ingredients on cardiovascularrelated outcomes as a diabetic complication. Regarding ginger, emerging evidence has indicated that ginger consumption might decrease the expression of sICAM-1 in diabetic nephropatic rats by decreasing inflammation and reducing the release of inflammatory mediators ${ }^{(18)}$. In an in vitro study, it was shown that ginger did influence the adhesion of endothelial cells by decreasing the intercellular adhesion molecule- $1^{(23)}$. We did not find any 
significant effect from the use of cinnamon and cardamom on serum sICAM-1 concentrations. In an in vitro study, cinnamon could significantly reduce sVCAM-1 and sICAM-1 levels through inhibiting TNF- $\alpha$ induced expression of endothelial factors, as well as at the transcriptional level through decreasing sVCAM-1 and sICAM-1 mRNA levels ${ }^{(24)}$. No previous publication has examined the effect of cardamom on endothelial function. Therefore, further studies are required to assess the effect of cardamom or its ingredients on human health.

Diabetic patients are at greater risk of hypertension. Therefore, finding an appropriate intervention which could led to controlled blood pressure in these patients are of great importance ${ }^{(25)}$. In the present study, ginger intake for eight weeks in diabetic patients resulted in a reduced SBP, but it did not affect diastolic blood pressure. In an experimental study, ginger intake resulted in a vasodilation in rats and rabbits, similar to that of verapamil ${ }^{(26)}$. In a systematic review, the hypotensive effect of ginger has been attributed to its effect on reducing low density lipoproteins and cholesterol levels. These particles can reduce the elasticity of arteries ${ }^{(13)}$. We did not find any significant effect of other herbal medicines on blood pressure in this study. In an experimental study, extended administration of crocin, a potentially bioactive component of saffron, could reduce SBP in hypertensive rats in a dose dependent manner by blocking calcium channels. However, the investigators failed to reach such an effect in normotensive rats ${ }^{(27)}$. Others have also confirmed the hypotensive effects of saffron in humans. Madaghegh et al found that the administration of $400 \mathrm{mg}$ saffron tablet to normal adults for 1 week resulted in reduced SBP ${ }^{(28)}$. Considering the limited evidence of the effect of saffron intake on blood pressure, further studies are required to reach a conclusion in this regard. Regarding cinnamon, a published study on humans indicated that consumption of cinnamon was associated with non-significantly reduction of SBP and DBP in T2DM patients. The authors have concluded that the possible reductions in SBP and DBP were 
strongly related to the patients' baseline BP levels(29). Although we failed to find a significant effect of cardamom intake on blood pressure, others have shown a beneficial effect of this herbal medicine on blood pressure. In an animal study, intravenous injections of cardamom to normotensive rats resulted in a dose-dependent fall in the arterial $\mathrm{BP}^{(30)}$. Verma et al. administered 3 grams of cardamom powder in two divided doses to twenty hypertensive individuals for 12 weeks. They found that cardamom intake significantly reduced SBP and DBP at the end of 12 th week ${ }^{(14)}$.

We did not find any significant effect of herbal medicines on anthropometric measurement in this study. Some studies have found that the consumption of three grams per day of cinnamon for eight weeks in diabetic patients resulted in a significant reduction in body weight ${ }^{(31)}$. Another study reported that ginger supplementation and progressive resistance training could significantly reduce waist circumference in obese men $^{(32)}$. Overall, data on the effect of herbal medicines on anthropometric measurement are scarce and conflicting. Additional data are required to clarify the effect of these medicines on body weight.

This study has some limitations which should be considered. A food record is unlikely to be an indicator of usual personal intake. The probability of measurement and laboratory error also exists. Our single blind studies as well as the differences in baseline characteristics are other limitations. Moreover large sample size (compared to other studies on herbal medicine), prospective design, and follow-up of participants are some of the strengths of the study. Comparing intervention groups with control groups allows for the ability to distinguish whether our results are from the herbal treatment or the usual diet. Another important strength was confounders were controlled, including the dietary pattern through five-day food records and physical activity by an IPAQ questionnaire, during 8 weeks of intervention. In addition, a 3-week run-in period before the intervention to make their tea consumption patterns similar was the other main strength. 
Conclusions: In conclusion, the consumption of cinnamon, cardamom, saffron and ginger as supplementary remedies could not significantly reduce the risk of CVD, as well as diabetes complications. More studies with longer duration and different doses on various age ranges could focus more on the importance of beneficial effects of herbal medicine in diabetic patients.

\section{ACKNOWLEDGEMENT:}

The authors would like to thank the individuals who participated in the present study. This study was supported by a financial grant from the "Iran National Science Foundation" and "Isfahan University of Medical Sciences".

Conflict of interest: This study was financially supported by "Iran National Science Foundation" and" Isfahan University of Medical Sciences, Isfahan, Iran.". None of the authors declared any potential personal or financial conflicts of interest. 


\section{REFFRENCES:}

1. Smyth S, Heron A, 2006. Diabetes and obesity: the twin epidemics. Nature Med. 12,75-80.

2. Meetoo D, Mcgovern P, Safadi R, 2007. An epidemiological overview of diabetes across the world. Br J Nurs. 16, 1002-1007.

3. Esteghamati A, Etemad K, Koohpayehzadeh J, Abbasi M, Meysamie A, Noshad S, Asgari F, Mousavizadeh M, Rafei A, Khajeh E, 2014. Trends in the prevalence of diabetes and impaired fasting glucose in association with obesity in Iran: 2005-2011. Diabetes Res Clin Pract. 103, 319-327.

4. Darko D, Dornhorst A, Kelly F, Ritter J, Chowienczyk P, 2002. Lack of effect of oral vitamin C on blood pressure, oxidative stress and endothelial function in Type II diabetes. Clin Sci. 103, 339-344.

5. Colhoun HM, Betteridge DJ, Durrington PN, Hitman GA, Neil HAW, Livingstone SJ, Thomason MJ, Mackness MI, Charlton-Menys V, Fuller JH, 2004. Primary prevention of cardiovascular disease with atorvastatin in type 2 diabetes in the Collaborative Atorvastatin Diabetes Study (CARDS): multicentre randomised placebo-controlled trial. Lancet. 364, 685696.

6. Hwang S-J, Ballantyne CM, Sharrett AR, Smith LC, Davis CE, Gotto AM, Boerwinkle E, 1997. Circulating adhesion molecules VCAM-1, ICAM-1, and E-selectin in carotid 
atherosclerosis and incident coronary heart disease cases the atherosclerosis risk in communities (ARIC) study. Circulation. 96, 4219-4225.

7. Mahn K, Borrás C, Knock GA, Taylor P, Khan IY, Sugden D, Poston L, Ward JP, Sharpe RM, Viña J, 2005. Dietary soy isoflavone induced increases in antioxidant and eNOS gene expression lead to improved endothelial function and reduced blood pressure in vivo. FASEB J. 19, 1755-1757.

8 Ferrari CK, 2004. Functional foods, herbs and nutraceuticals: towards biochemical mechanisms of healthy aging. Biogerontology. 5, 275-289.

9. Kelble A, 2005. Spices and type 2 diabetes. Nutr \& Food Sci. 35, 81-87.

10. Fitzpatrick DF, Hirschfield SL, Ricci T, Jantzen P, Coffey RG, 1995. Endotheliumdependent vasorelaxation caused by various plant extracts. Nutr \& Food Sci. 26, 90-95.

11. Qin B, Panickar KS, Anderson RA, 2010. Cinnamon: potential role in the prevention of insulin resistance, metabolic syndrome, and type 2 diabetes. J Diabetes Sci Technol. 4, 685693.

12. Akilen R, Pimlott Z, Tsiami A, Robinson N, 2013. Effect of short-term administration of cinnamon on blood pressure in patients with prediabetes and type 2 diabetes. Nutrition. 29, 1192-1196.

13. Kaur R, Khannab N, 2012. Pathophysiology and risk factors related to hypertension and its cure using herbal drugs. Spatula DD. 2, 245-256.

14. Verma S, Jain V, Katewa S, 2009. Blood pressure lowering, fibrinolysis enhancing and antioxidant activities of Cardamom (Elettaria cardamomum). Indian J Biochem Biophys. 46, 503-506.

15. Xi L, Qian Z, Xu G, Zheng S, Sun S, Wen N, Sheng L, Shi Y, Zhang Y, 2007. Beneficial impact of crocetin, a carotenoid from saffron, on insulin sensitivity in fructose-fed rats. J Nutr Biochem. 18, 64-72. 
16. He S-Y, Qian Z-Y, Wen N, Tang F-T, Xu G-L, Zhou C-H, 2007. Influence of crocetin on experimental atherosclerosis in hyperlipidamic-diet quails. Eur J Phycol. 554, 191-195.

17. Imenshahidi M, Hosseinzadeh H, Javadpour Y, 2010. Hypotensive effect of aqueous saffron extract (Crocus sativus L.) and its constituents, safranal and crocin, in normotensive and hypertensive rats. Phytother Res. 24, 990-994.

18. Tzeng T-F, Liou S-S, Chang CJ, Liu I-M, 2013. Zerumbone, a tropical ginger sesquiterpene, ameliorates streptozotocin-induced diabetic nephropathy in rats by reducing the hyperglycemia-induced inflammatory response. Nutr Metab. 10, 64-76.

19. Craig C, Marshall A, Sjöström M, Bauman A, Booth M, Ainsworth B, Pratt M, Ekelund U, Yngve A, Sallis J. and the IPAQ Consensus Group and the IPAQ Reliability and Validity Study Group, 2003. International Physical Activity Questionnaire (IPAQ): 12-country reliability and validity. Med Sci Sports Exerc. 35, 1381-1395.

20. De Vriese AS, Verbeuren TJ, Van de Voorde J, Lameire NH, Vanhoutte PM, 2000. Endothelial dysfunction in diabetes. Br J Pharmacol. 130, 963-974.

21. Elhadd T, Kennedy G, Robb R, McLaren M, Jung R, Belch J, 2004. Elevated soluble cell adhesion molecules E-selectin and intercellular cell adhesion molecule-1 in type-2 diabetic patients with and without asymptomatic peripheral arterial disease. Int Angiol. 23, 128-133.

22. Xiang M, Qian Z-Y, Zhou C-H, Liu J, Li W-N, 2006. Crocetin inhibits leukocyte adherence to vascular endothelial cells induced by AGEs. J Ethnopharmacol. 107, 25-31.

23. Song Y, Wei X, Ding H, Cheng X, 2007. Influence of effective part of Zingiber officinal on expression of monocyte chemotactic protein- 1 and adhesion molecules. China journal of Chinese materia medica. 32, 2062-2065.

24. Liao B-C, Hsieh C-W, Liu Y-C, Tzeng T-T, Sun Y-W, Wung B-S, 2008. Cinnamaldehyde inhibits the tumor necrosis factor- $\alpha$-induced expression of cell adhesion 


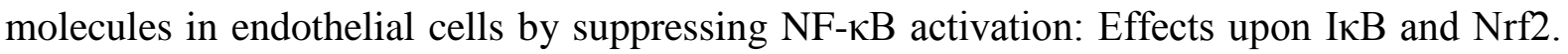
Toxicol Appl Pharmacol. 229, 161-171.

25. Group UPDS, 1998. Tight blood pressure control and risk of macrovascular and microvascular complications in type 2 diabetes: UKPDS 38. BMJ. 317, 703-713.

26. Ghayur MN, Gilani AH, 2005. Ginger lowers blood pressure through blockade of voltage-dependent calcium channels. J Cardiovasc Pharmacol.45, 74-80.

27. Imenshahidi M, Razavi BM, Faal A, Gholampoor A, Mousavi SM, Hosseinzadeh H, 2014. Effects of chronic crocin treatment on desoxycorticosterone acetate (doca)-salt hypertensive rats. Iran J Basic Med Sci. 17, 9-13.

28. Modaghegh M-H, Shahabian M, Esmaeili H-A, Rajbai O, Hosseinzadeh H, 2008. Safety evaluation of saffron (Crocus sativus tablets in healthy volunteers. Phytomedicine. 15, 10321037.

29. Wainstein J, Stern N, Heller S, Boaz M, 2011. Dietary cinnamon supplementation and changes in systolic blood pressure in subjects with type 2 diabetes. J Med Food. 14, 15051510.

30. Lund-Johansen P, 1998. Hemodynamic effects of calcium antagonists in hypertension. second ed. Hanley \& Belfus, Philadelphia.

31. Vafa M, Mohammadi F, Shidfar F, Sormaghi MS, Heidari I, Golestan B, Amiri F, 2012. Effects of cinnamon consumption on glycemic status, lipid profile and body composition in type 2 diabetic patients. Int J Prev Med. 3, 531-536.

32. Atashak S, Peeri M, Azarbayjani MA, Stannard SR, Haghighi MM, 2011. Obesity-related cardiovascular risk factors after long-term resistance training and ginger supplementation. $\mathrm{J}$ Sports Sci Med. 10, 685-691. 
Table 1. Baseline characteristics of people with diabetes in five groups ${ }^{1}$

\begin{tabular}{|c|c|c|c|c|c|c|c|}
\hline Baseline characteristics & $\begin{array}{c}\text { Total } \\
(n=204)\end{array}$ & $\begin{array}{l}\text { Cinnamon } \\
(n=40)\end{array}$ & $\begin{array}{c}\text { Cardamom } \\
(n=42)\end{array}$ & $\begin{array}{l}\text { Saffron } \\
(n=42)\end{array}$ & $\begin{array}{l}\text { Ginger } \\
(n=41)\end{array}$ & $\begin{array}{l}\text { Control } \\
(n=39)\end{array}$ & p-value \\
\hline Age (year) & $54.33 \pm 0.5$ & $54.15 \pm 1.0$ & $51.59 \pm 1.3$ & $57.02 \pm 1.0$ & $55.21 \pm 1.1$ & $53.64 \pm 1.3$ & $0.02 *$ \\
\hline men/women (number) & $79 / 125$ & $16 / 24$ & $17 / 25$ & $16 / 26$ & $15 / 26$ & $15 / 24$ & 0.99 \\
\hline Weight (kg) & $78.90 \pm 0.5$ & $75.62 \pm 1.2$ & $78.61 \pm 1.2$ & $81.97 \pm 1.0$ & $79.39 \pm 0.9$ & $78.74 \pm 1.2$ & $0.005^{*}$ \\
\hline Waist (cm) & $102.41 \pm 0.6$ & $102.80 \pm 1.5$ & $101.47 \pm 1.4$ & $102.26 \pm 1.5$ & $104.56 \pm 1.3$ & $100.92 \pm 1.4$ & 0.46 \\
\hline BMI (kg/m2) & $28.82 \pm 0.1$ & $28.78 \pm 0.2$ & $28.96 \pm 0.2$ & $28.86 \pm 0.2$ & $29.05 \pm 0.2$ & $28.40 \pm 0.2$ & 0.39 \\
\hline $\begin{array}{l}\text { Physical activity } \\
\text { (Met h/week) }\end{array}$ & $24.33 \pm 0.2$ & $24.17 \pm 0.6$ & $24.35 \pm 0.7$ & $24.59 \pm 0.6$ & $23.60 \pm 0.6$ & $24.96 \pm 0.6$ & 0.67 \\
\hline
\end{tabular}

1. All values are Mean \pm SE (Standard Error).

*Significant differences between groups. 
Table 2. Dietary intakes of the study participants' period of intervention in five groups ${ }^{1}$

\begin{tabular}{|c|c|c|c|c|c|c|c|}
\hline Nutrient & $\begin{array}{c}\text { Total } \\
(n=204)\end{array}$ & $\begin{array}{l}\text { Cinnamon } \\
(\mathrm{n}=40)\end{array}$ & $\begin{array}{l}\text { Cardamom } \\
(\mathrm{n}=42)\end{array}$ & $\begin{array}{l}\text { Saffron } \\
(n=42)\end{array}$ & $\begin{array}{l}\text { Ginger } \\
(n=41)\end{array}$ & $\begin{array}{l}\text { Control } \\
(n=39)\end{array}$ & p-value \\
\hline Energy intake (kcal/d) & $2306.60 \pm 23.7$ & $2318.13 \pm 54.8$ & $2311.67 \pm 53.0$ & $2306.79 \pm 54.7$ & $2310.52 \pm 48.9$ & $2284.92 \pm 56.4$ & 0.99 \\
\hline Protein (g/d) & $61.64 \pm 1.2$ & $58.90 \pm 2.7$ & $63.57 \pm 2.9$ & $61.26 \pm 3.0$ & $60.73 \pm 2.3$ & $63.76 \pm 2.6$ & 0.71 \\
\hline $\operatorname{Vitamin} \mathrm{A}(\mu \mathrm{g} / \mathrm{d})$ & $655.25 \pm 11.4$ & $609.45 \pm 20.5$ & $666.92 \pm 26.3$ & $652.80 \pm 28.5$ & $655.95 \pm 22.4$ & $691.53 \pm 28.7$ & 0.26 \\
\hline Vitamin C(mg/d) & $53.66 \pm 0.8$ & $55.42 \pm 2.0$ & $54.21 \pm 2.0$ & $53.90 \pm 2.0$ & $53.30 \pm 1.7$ & $51.38 \pm 1.9$ & 0.70 \\
\hline Vitamin E(mg/d) & $8.95 \pm 0.1$ & $9.01 \pm 0.2$ & $8.97 \pm 0.2$ & $9.05 \pm 0.3$ & $8.88 \pm 0.2$ & $8.84 \pm 0.3$ & 0.98 \\
\hline $\operatorname{Vitamin} \mathrm{D}(\mu \mathrm{g} / \mathrm{d})$ & $9.49 \pm 0.1$ & $8.80 \pm 0.3$ & $9.72 \pm 0.4$ & $9.43 \pm 0.4$ & $9.47 \pm 0.3$ & $10.05 \pm 0.4$ & 0.25 \\
\hline Vitamin B1(mg/d) & $0.97 \pm 0.02$ & $0.98 \pm 0.04$ & $0.98 \pm 0.04$ & $0.99 \pm 0.04$ & $0.94 \pm 0.04$ & $0.96 \pm 0.05$ & 0.95 \\
\hline Vitamin B2(mg/d) & $1.06 \pm 0.01$ & $1.03 \pm 0.03$ & $1.06 \pm 0.04$ & $1.06 \pm 0.04$ & $1.08 \pm 0.03$ & $1.07 \pm 0.04$ & 0.93 \\
\hline Vitamin B6(mg/d) & $1.40 \pm 0.01$ & $1.43 \pm 0.03$ & $1.40 \pm 0.04$ & $1.43 \pm 0.04$ & $1.40 \pm 0.03$ & $1.36 \pm 0.04$ & 0.76 \\
\hline Vitamin B12 $(\mu \mathrm{g} / \mathrm{d})$ & $1.44 \pm 0.02$ & $1.44 \pm 0.05$ & $1.43 \pm 0.05$ & $1.45 \pm 0.05$ & $1.45 \pm 0.04$ & $1.43 \pm 0.05$ & 0.99 \\
\hline Vitamin $B 9(\mu \mathrm{g} / \mathrm{d})$ & $349.94 \pm 2.0$ & $353.15 \pm 5.3$ & $349.52 \pm 4.2$ & $349.76 \pm 4.7$ & $350.16 \pm 4.1$ & $347.05 \pm 3.8$ & 0.92 \\
\hline Calcium(mg/d) & $682.63 \pm 11.6$ & $690.82 \pm 27.0$ & $676.26 \pm 26.3$ & $688.07 \pm 26.9$ & $684.73 \pm 22.1$ & $673.00 \pm 28.7$ & 0.98 \\
\hline Ferritin (mg/d) & $6.71 \pm 0.1$ & $6.60 \pm 0.2$ & $6.75 \pm 0.2$ & $6.73 \pm 0.2$ & $6.71 \pm 0.2$ & $6.77 \pm 0.2$ & 0.99 \\
\hline $\operatorname{zinc}(\mathrm{mg} / \mathrm{d})$ & $7.60 \pm 0.08$ & $7.55 \pm 0.2$ & $7.59 \pm 0.1$ & $7.60 \pm 0.2$ & $7.53 \pm 0.1$ & $7.71 \pm 0.1$ & 0.96 \\
\hline Selenium $(\mu \mathrm{g} / \mathrm{d})$ & $41.07 \pm 0.43$ & $42.59 \pm 1.04$ & $40.52 \pm 0.96$ & $41.96 \pm 1.0$ & $40.65 \pm 0.88$ & $39.58 \pm 0.89$ & 0.20 \\
\hline Iodine $(\mu \mathrm{g} / \mathrm{d})$ & $141.67 \pm 0.7$ & $140.37 \pm 1.6$ & $141.35 \pm 1.6$ & $141.54 \pm 1.9$ & $142.07 \pm 1.6$ & $143.07 \pm 1.8$ & 0.87 \\
\hline
\end{tabular}


Table 3. Anthropometric and Biomarkers of patients before and after 8 weeks in cinnamon, cardamom, saffron, ginger and control groups ${ }^{1}$

\begin{tabular}{|c|c|c|c|c|c|c|c|}
\hline Biomarkers & & $\begin{array}{l}\text { Cinnamon } \\
(\mathrm{n}=40)\end{array}$ & $\begin{array}{l}\text { Cardamom } \\
(\mathrm{n}=42)\end{array}$ & $\begin{array}{l}\text { Saffron } \\
(n=42)\end{array}$ & $\begin{array}{l}\text { Ginger } \\
(n=41)\end{array}$ & $\begin{array}{l}\text { Control } \\
(n=39)\end{array}$ & p-value ${ }^{3}$ \\
\hline \multirow[t]{3}{*}{ weight(kg) } & baseline & $75.62 \pm 1.2$ & $78.61 \pm 1.2$ & $81.97 \pm 1.0$ & $79.39 \pm 0.97$ & $78.74 \pm 1.2$ & 0.43 \\
\hline & 8 weeks & $75.32 \pm 1.2$ & $78.50 \pm 1.2$ & $81.90 \pm 0.99$ & $79.21 \pm 0.96$ & $78.48 \pm 1.1$ & \\
\hline & $\mathrm{p}$-value ${ }^{2}$ & $0.07 * *$ & 0.49 & 0.64 & 0.25 & 0.34 & \\
\hline \multirow[t]{2}{*}{ BMI(kg/m2) } & baseline & $28.78 \pm 0.2$ & $28.96 \pm 0.2$ & $28.86 \pm 0.2$ & $29.05 \pm 0.2$ & $28.40 \pm 0.2$ & 0.16 \\
\hline & 8 weeks & $28.68 \pm 0.2$ & $28.89 \pm 0.2$ & $28.84 \pm 0.2$ & $29.08 \pm 0.2$ & $28.26 \pm 0.1$ & \\
\hline \multirow[t]{3}{*}{ waist(cm) } & baseline & $102.80 \pm 1.5$ & $101.47 \pm 1.4$ & $102.26 \pm 1.5$ & $104.56 \pm 1.3$ & $100.92 \pm 1.4$ & 0.96 \\
\hline & 8 weeks & $102.45 \pm 1.5$ & $101.07 \pm 1.4$ & $102.02 \pm 1.5$ & $104.17 \pm 1.3$ & $100.66 \pm 1.4$ & \\
\hline & p-value & 0.11 & $0.09 * *$ & 0.27 & $0.06 * *$ & 0.40 & \\
\hline \multirow[t]{3}{*}{ sICAM-1(ng/ml) } & baseline & $297.22 \pm 15.3$ & $336.64 \pm 17.02$ & $340.9 \pm 14.4$ & $391.78 \pm 16.0$ & $302.41 \pm 13.7$ & 0.58 \\
\hline & 8 weeks & $297.60 \pm 15.2$ & $336.83 \pm 16.8$ & $339.69 \pm 14.4$ & $390.97 \pm 15.8$ & $302.69 \pm 13.9$ & \\
\hline & p-value & 0.65 & 0.76 & $0.01^{*}$ & $0.009 *$ & 0.78 & \\
\hline & 8 weeks & $133.0 \pm 0.2$ & $143.6 \pm 0.2$ & $139.0 \pm 0.1$ & $142.7 \pm 0.2$ & $137.2 \pm 0.2$ & \\
\hline & $\mathrm{p}$-value & 0.11 & 0.80 & 0.36 & $0.02 *$ & 0.72 & \\
\hline \multirow[t]{3}{*}{ DBP(mmHg) } & baseline & $86.2 \pm 0.1$ & $95.2 \pm 0.1$ & $94.6 \pm 0.1$ & $97.6 \pm 0.1$ & $92.7 \pm 0.1$ & 0.16 \\
\hline & 8 weeks & $86.6 \pm 0.1$ & $95.5 \pm 0.1$ & $94.2 \pm 0.1$ & $97.9 \pm 0.1$ & $93.9 \pm 0.1$ & \\
\hline & p-value & 0.70 & 0.66 & 0.60 & 0.39 & 0.17 & \\
\hline
\end{tabular}

1. All values are Mean \pm SE (Standard Error).

2. for comparison of with-in group differences by paired t-test.

3. for comparison of between-group differences by MANCOVA.

*Significantly different from baseline values (student paired t-test) $\mathrm{p}<0.05$

** Marginally significant different from baseline values (student paired t-test) $\mathrm{p}<0.1$. 